\title{
Perfilhamento, área foliar e produtividade do milho sob diferentes arranjos espaciais
}

\author{
Luís Sangoi(1), Cleber Schweitzer(1), Paulo Regis Ferreira da Silva(2), Amauri Schmitt(1), \\ Vitor Paulo Vargas ${ }^{(1)}$, Ricardo Trezzi Casa(1) e Clóvis Arruda de Souza ${ }^{(1)}$
}

\begin{abstract}
(1)Universidade do Estado de Santa Catarina, Centro de Ciências Agroveterinárias, Avenida Luiz de Camões, no 2.090, CEP 88520-000 Lages, SC. E-mail: a2ls@cav.udesc.br, cleber@agronomo.eng.br, amauri.schmitt@agronomo.eng.br, vitorpvargas@hotmail.com, a2rtc@cav.udesc.br, a2cas@cav.udesc.br (2)Universidade Federal do Rio Grande do Sul, Faculdade de Agronomia, Avenida Bento Gonçalves, № 7.712, CEP 90001-970 Porto Alegre, RS. E-mail: paulo.silva@ufrgs.br
\end{abstract}

\begin{abstract}
Resumo - O objetivo deste trabalho foi avaliar o efeito de variações no arranjo espacial de plantas sobre o perfilhamento, a área foliar e a produtividade do milho. Os experimentos foram implantados na primavera/ verão dos anos agrícolas 2007/2008 e 2008/2009. Os tratamentos consistiram de quatro densidades (três, cinco, sete e nove plantas por metro quadrado) e de três espaçamentos entre linhas $(0,4,0,7$ e 1,0 m). Foram avaliados o índice de área foliar (IAF) e a produtividade de grãos do híbrido P30F53, além da contribuição dos perfílhos para esses caracteres. Em 2007/2008, não houve deficiência hídrica, o IAF na floração foi superior a 7 e os perfilhos contribuíram com $65 \%$ do IAF total, na menor densidade de plantas. Nesse ano, a produtividade de grãos (13,7 Mg ha $\left.{ }^{-1}\right)$ não foi afetada pelos tratamentos, e os perfilhos contribuíram com $44 \%$ da produtividade, na densidade de três plantas por metro quadrado. Em 2008/2009, houve restrição hídrica na pré-floração e no enchimento de grãos, o que diminuiu o perfilhamento e a contribuição dos perfilhos ao IAF. A produtividade de grãos, nesse ano, aumentou de 9,7 para $11,7 \mathrm{Mg} \mathrm{ha}^{-1}$ com o aumento na densidade de plantas, mas a contribuição dos perfilhos à produtividade foi menor. O perfilhamento aumenta a estabilidade fenotípica da produtividade de grãos frente a variações no arranjo de plantas.
\end{abstract}

Termos para indexação: Zea mays, densidade de plantas, espaçamento entre linhas, perfilhos.

\section{Maize tillering, leaf area, and grain productivity under different spatial arrangement}

\begin{abstract}
The objective of this work was to evaluate the effect of plant spatial arrangement on maize tillering, leaf area, and grain productivity. The experiments were carried out in the spring/summer of the 2007/2008 and 2008/2009 growing seasons. Treatments consisted of four plant densities (three, five, seven, and nine plants per square meter) and three row spacings $(0.4,0.7$, and $1.0 \mathrm{~m})$. The leaf area index (LAI) and grain yield of hybrid P30F53 were assessed, as well as the tiller contribution to these characters. In 2007/2008, there was no water deficit, LAI values were higher than 7 , and tillers contributed with $65 \%$ of total LAI at the lowest plant density. In this year, grain yield average $\left(13.7 \mathrm{Mg} \mathrm{ha}^{-1}\right)$ was not affected by treatments, and tillers contributed with $44 \%$ of total yield at the density of three plants per square meter. In 2008/2009, there was water deficit before flowering and during grain filling, which decreased tillering and tiller contribution to LAI. Grain yield in this year increased from 9.7 to $11.7 \mathrm{Mg} \mathrm{ha}^{-1}$ with increasing plant densities, but tiller contribution to grain yield was lower. Tillering increases phenotypic stability of grain productivity to variations in plant spatial arrangement.
\end{abstract}

Index terms: Zea mays, plant density, row spacing, tillers.

\section{Introdução}

Entre os cereais de importância econômica, o milho (Zea mays L.) é o de menor capacidade de perfilhamento. Essa característica pode ser atribuída ao processo de seleção genética, já que, durante a evolução do teosinto, houve priorização da dominância apical, com redução do número de ramificações laterais e concentração de toda a energia da planta no colmo principal (Doebley, 2004).
Os perfilhos são estruturas utilizadas pelas plantas da família Poaceae para a compensação de espaços vazios dentro da comunidade, no campo e na lavoura. Nas espécies em que o perfilhamento é comum, como o trigo e o arroz, os perfilhos são benéficos, pois aumentam o número de inflorescências por área e contribuem para incrementar a produtividade de grãos (Almeida et al., 2004). No milho, os perfilhos apresentam atraso na emergência de folhas, em comparação ao colmo principal (Moulia et al., 1999).

Pesq. agropec. bras., Brasília, v.46, n.6, p.609-616, jun. 2011 
Esse atraso, que está em torno de cinco folhas, é maior do que em outras poáceas e resulta em uma assincronia de desenvolvimento, o que faz com que os perfilhos sejam dominados pelo colmo principal e não produzam espigas (Akman, 2002).

O arranjo de plantas é uma das práticas culturais que mais interfere na produtividade do milho. Essa resposta está associada ao fato de que, diferentemente de outras poáceas, o milho não apresenta um mecanismo eficiente de compensação de espaços, pois perfilha pouco e apresenta baixa prolificidade e limitada capacidade de expansão (Strieder et al., 2007).

O surgimento de híbridos com alto potencial produtivo e elevada capacidade de produção de perfilhos indica que essas estruturas podem contribuir para a produtividade de grãos de milho, principalmente em lavouras implantadas com baixas densidades de plantas (Sangoi et al., 2009). A redução do espaçamento entre linhas, mantendo-se a densidade constante, promove a distribuição mais equidistante de plantas na lavoura. $\mathrm{O}$ arranjo mais favorável de plantas propiciado pela aproximação de linhas de semeadura pode estimular as taxas de crescimento da cultura no início do ciclo e, consequentemente, reduzir a dominância apical e favorecer a emissão, a sobrevivência e a contribuição dos perfilhos para a produtividade do milho (Sangoi et al., 2009).

No ano agrícola de 2009/2010, a produtividade média de grãos de milho no Brasil foi de 4,1 $\mathrm{Mg} \mathrm{ha}^{-1}$ (Companhia Nacional de Abastecimento, 2010). Essa baixa produtividade pode ser explicada em parte pela implantação de lavouras com populações de plantas abaixo da recomendada, já que é comum encontrar lavouras com densidades inferiores a 50.000 plantas por hectare, na colheita.

A produtividade de grãos de uma comunidade pode ser incrementada ao se maximizar a sua eficiência fotossintética, o que pode ser obtido pela melhoria da interceptação da radiação fotossinteticamente ativa pelo dossel (Marchão et al., 2006). Como o milho apresenta baixa capacidade de expansão foliar, estandes reduzidos limitam a interceptação de radiação solar pela lavoura e diminuem a sua produtividade (Sangoi et al., 2007). Dessa forma, o aproveitamento dos perfilhos pode ser uma estratégia para compensar espaços vazios e incrementar o número de colmos por área, o índice de área foliar e a interceptação da radiação solar (Sangoi et al., 2009).

Oobjetivo deste trabalho foi avaliar o efeito de variações no arranjo espacial de plantas sobre o perfilhamento, a área foliar e a produtividade do milho.

\section{Material e Métodos}

O experimento foi conduzido a campo, no Município de Lages, SC, durante o período primavera/verão dos anos agrícolas 2007/2008 e 2008/2009. O solo da área experimental é classificado como Nitossolo Vermelho distrófico típico (Santos et al., 2006), e os resultados da análise química indicaram: $460 \mathrm{~g} \mathrm{~kg}^{-1}$ de argila; $\mathrm{pH}$ em $\mathrm{H}_{2} \mathrm{O}$ de 6,$7 ; 3,3 \mathrm{mg} \mathrm{L}^{-1}$ de $\mathrm{P} ; 0,43 \mathrm{cmol}_{\mathrm{c}} \mathrm{dm}^{-3}$ de $\mathrm{K} ; 39 \mathrm{~g} \mathrm{~kg}^{-1}$ de matéria orgânica; $11 \mathrm{cmol}_{\mathrm{c}} \mathrm{dm}^{-3}$ de $\mathrm{Ca} ; 6,5 \mathrm{cmol}_{\mathrm{c}} \mathrm{dm}^{-3}$ de $\mathrm{Mg} ; 0,0 \mathrm{cmol}_{\mathrm{c}} \mathrm{dm}^{-3}$ de Al; e 20,78 $\mathrm{cmol}_{\mathrm{c}} \mathrm{dm}^{-3}$ de CTC. A área experimental encontrava-se em rotação com soja (Glycine max L.) e sucessão com aveia-preta (Avena strigosa Schreb.).

Utilizou-se o delineamento experimental de blocos ao acaso, disposto em parcelas subdivididas, com quatro repetições. Os tratamentos nas parcelas principais consistiram de quatro densidades de plantas: três, cinco, sete e nove plantas por metro quadrado. Já nas subparcelas, foram avaliados três espaçamentos entre linhas: $0,4,0,7$ e 1,0 m. As subparcelas eram constituídas de cinco linhas, com $6 \mathrm{~m}$ de comprimento. A área útil era compreendida pelas três linhas centrais de cada subparcela, tendo-se desprezado $0,5 \mathrm{~m}$ na extremidade de cada linha.

Os experimentos foram implantados em 19/10/2007 e 15/11/2008, com uso de semeadura direta. Adistribuição das sementes foi feita com semeadoras manuais, tendose colocado três sementes por cova do híbrido simples de milho P30F53, de ciclo precoce, com grãos duros e alaranjados. Quando as plantas estavam no estádio fenológico de três folhas expandidas (V3), conforme escala proposta por Ritchie et al. (1993), foi realizado o desbaste, tendo-se deixado o número de plantas necessário para atingir as densidades esperadas.

Em ambos os períodos de avaliação, a adubação utilizada foi determinada de acordo com os resultados da análise do solo, para alcançar produtividades de 12,0 $\mathrm{Mg} \mathrm{ha}^{-1}$. Foram aplicados, na semeadura, $30 \mathrm{~kg} \mathrm{ha}^{-1} \mathrm{de} \mathrm{N}, 205 \mathrm{~kg} \mathrm{ha}^{-1} \mathrm{de}_{2} \mathrm{P}_{2} \mathrm{O}_{5}$ e $110 \mathrm{~kg} \mathrm{ha}^{-1}$ de $\mathrm{K}_{2} \mathrm{O}$. A aplicação de $\mathrm{N}$ em cobertura foi dividida em duas frações, com metade $\left(100 \mathrm{~kg} \mathrm{ha}^{-1}\right)$ aplicada em V4 e metade (100 $\left.\mathrm{kg} \mathrm{ha}^{-1}\right)$ em V8, o que totalizou $230 \mathrm{~kg} \mathrm{ha}^{-1}$ de $\mathrm{N}$ por safra.

Por ocasião da semeadura, foi realizado o controle preventivo de plantas daninhas com aplicação de herbicida, em pré-emergência, tendo-se utilizado uma mistura de atrazina e s-metolacloro $\left(1.480+1.160 \mathrm{~g} \mathrm{ha}^{-1}\right.$ de i.a.). Quando as plantas se encontravam em V3, o 
controle das plantas daninhas foi complementado com a aplicação do herbicida tembotrione $\left(100,8 \mathrm{~g} \mathrm{ha}^{-1} \mathrm{de}\right.$ i.a.). O controle da lagarta-do-cartucho (Spodoptera frugiperda) foi feito pela aplicação do inseticida lufenuron (15 $\mathrm{g} \mathrm{ha}^{-1}$ de i.a.), sempre que as plantas apresentavam sintomas de raspagem nas folhas.

A radiação fotossinteticamente ativa interceptada pela cultura foi calculada pela fórmula $\left(1-\mathrm{I}_{t} / \mathrm{I}_{0}\right)$ x 100 , em que $I_{t}$ é a radiação fotossinteticamente ativa (PAR) incidente abaixo da camada de folhas fotossinteticamente ativas, e $\mathrm{I}_{0}$ é a PAR incidente no topo do dossel. Os valores de $\mathrm{I}_{\mathrm{t}}$ e $\mathrm{I}_{0}$ foram obtidos com um radiômetro de sensor quântico plano modelo LI-190 (Li-Cor, Lincoln, Nebraska, EUA), que determina a densidade de fluxo de fótons fotossinteticamente ativos (DFFFA, $\lambda=400-700 \mathrm{~nm}$ ), conectado à um datalogger modelo Li-1400 (Li-Cor, Lincoln, Nebraska, EUA). As determinações foram realizadas quando as plantas encontravam-se nos estádios fenológicos V6 (seis folhas expandidas), V15 (quinze folhas expandidas), VT (pendoamento) e R3 (grão leitoso), segundo escala de Ritchie et al. (1993). Foram amostrados cinco pontos por unidade experimental. As medições foram feitas entre 11 e $13 \mathrm{~h}$, em dias sem presença de nuvens.

A área foliar do colmo principal foi obtida pela expressão $\mathrm{AF}=\mathrm{C} \times \mathrm{L} \times 0,75$, também utilizada por Sangoi et al. (2007), em que C e L representam o comprimento e a largura, respectivamente, de todas as folhas com mais de $50 \%$ de área verde, de quatro plantas por subparcela. $\mathrm{O}$ índice de área foliar (IAF) foi estimado pela relação entre a área foliar e o espaço ocupado pelas plantas em cada tratamento. Já a área foliar dos perfilhos, foi calculada pela mesma fórmula matemática usada para medir a área foliar do colmo principal, em um perfilho representativo das plantas. O IAF dos perfilhos foi obtido pela divisão da área foliar média dos perfilhos pelo espaço ocupado por eles em cada subparcela.

Na colheita, foi contado o número de plantas com perfilhos férteis e determinada a percentagem de plantas com espigas nos perfilhos. A colheita foi realizada manualmente em 25/4/2008 e 5/5/2009, quando a umidade de grãos estava entre 18 e $22 \%$. As espigas produzidas nos colmos principais e nos perfilhos foram colhidas separadamente para determinar a contribuição dos perfilhos à produtividade da cultura. As espigas foram trilhadas mecanicamente e os grãos secos em estufa a $60^{\circ} \mathrm{C}$, até atingir peso constante.
Após a secagem, os grãos foram limpos em máquina de ar e peneira para padronização quanto à qualidade. A produtividade de grãos do colmo principal, dos perfilhos e total (colmo principal + perfilhos) foi convertida para $\mathrm{kg} \mathrm{ha}^{-1}$ e expressa na umidade padrão de $130 \mathrm{~g} \mathrm{~kg}^{-1}$.

O balanço hídrico da cultura foi realizado de acordo com a metodologia de Thorntwaite \& Mather, descrita por Bergamaschi (1999). O cálculo da evapotranspiração potencial (ETP) foi feito pela multiplicação da evaporação do tanque classe A pelo coeficiente do tanque $(\mathrm{Kp})$. Esses dados e os registros meteorológicos foram obtidos na estação meteorológica da Universidade do Estado de Santa Catarina, situada a $10 \mathrm{~km}$ de distância da área experimental.

Os dados obtidos foram submetidos à análise de variância, com uso do programa estatístico WinStat. Os valores de $\mathrm{F}$ para os efeitos principais e as interações foram considerados significativos a 5\% de probabilidade. Quando alcançada significância, foram ajustadas as regressões e selecionado o modelo matemático que melhor descrevesse o comportamento das características avaliadas.

\section{Resultados e Discussão}

No ano agrícola 2007/2008, observou-se adequada distribuição da precipitação pluvial e, consequentemente, não houve deficiência hídrica para a cultura do milho (Figura $1 \mathrm{~A}$ ). A precipitação acumulada durante o ciclo foi de $526 \mathrm{~mm}$, enquanto a demanda de água pela cultura foi de $450 \mathrm{~mm}$. Na primavera/verão de 2008/2009, a precipitação pluvial apresentou distribuição irregular durante o ciclo, com momentos de excesso hídrico e de deficiência hídrica (Figura $1 \mathrm{~B}$ ). Houve dois períodos de restrição hídrica: o primeiro ocorreu entre o estádio V15 e o espigamento (R1), e o segundo no final do enchimento de grãos, a partir de $\mathrm{R} 4$. A precipitação acumulada durante o ciclo foi de $417 \mathrm{~mm}$, enquanto a demanda da cultura foi de $431 \mathrm{~mm}$.

Nos dois anos agrícolas, a radiação solar interceptada pelo dossel do milho foi afetada pelo efeito simples do espaçamento entre linhas, quando o milho estava em V6. Em 2007/2008, houve redução quadrática na radiação interceptada com o aumento do espaçamento entre linhas (Figura 2). Nesta fase inicial do ciclo da cultura, a radiação interceptada foi de $12,6 \%$, no espaçamento de $0,4 \mathrm{~m}$ entre linhas, tendo diminuído para 

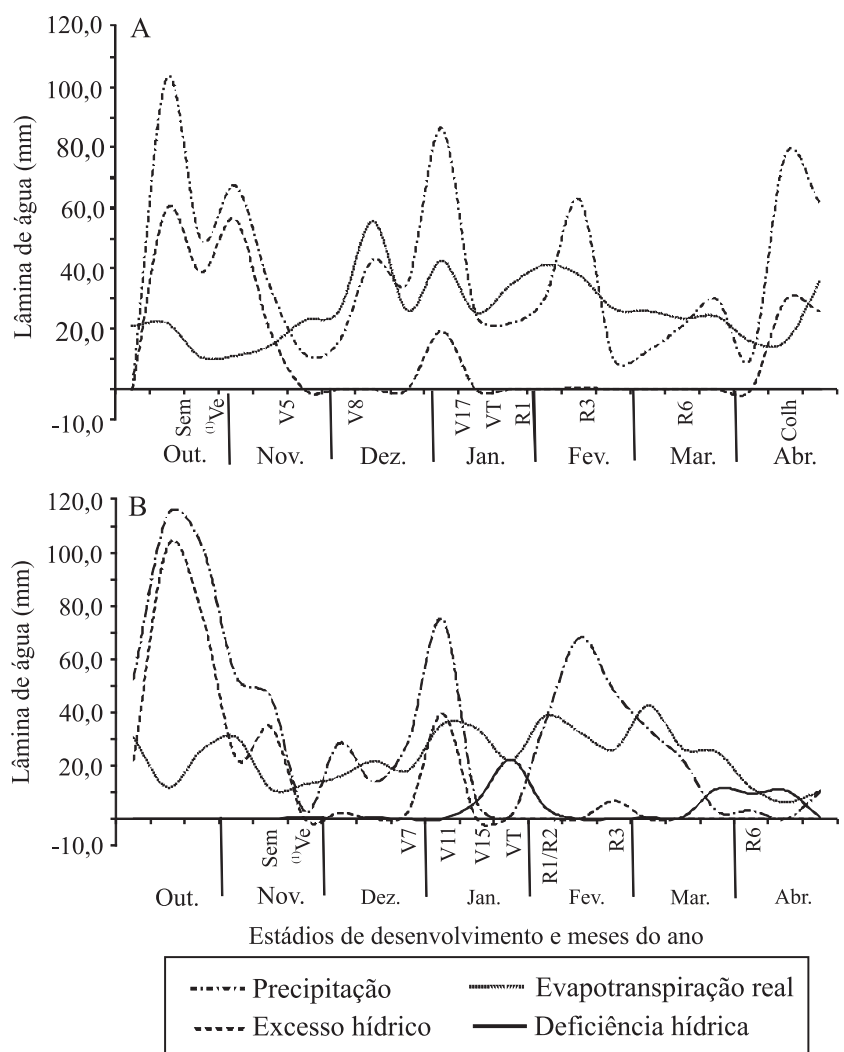

Figura 1. Balanço hídrico decendial do ano agrícola 2007/2008 (A) e 2008/2009 (B), segundo metodologia proposta por Thorntwaite \& Mather, tendo-se considerado a capacidade de armazenamento de água no solo de $75 \mathrm{~mm} .{ }^{(1)}$ Conforme escala de desenvolvimento proposta por Ritchie et al. (1993).

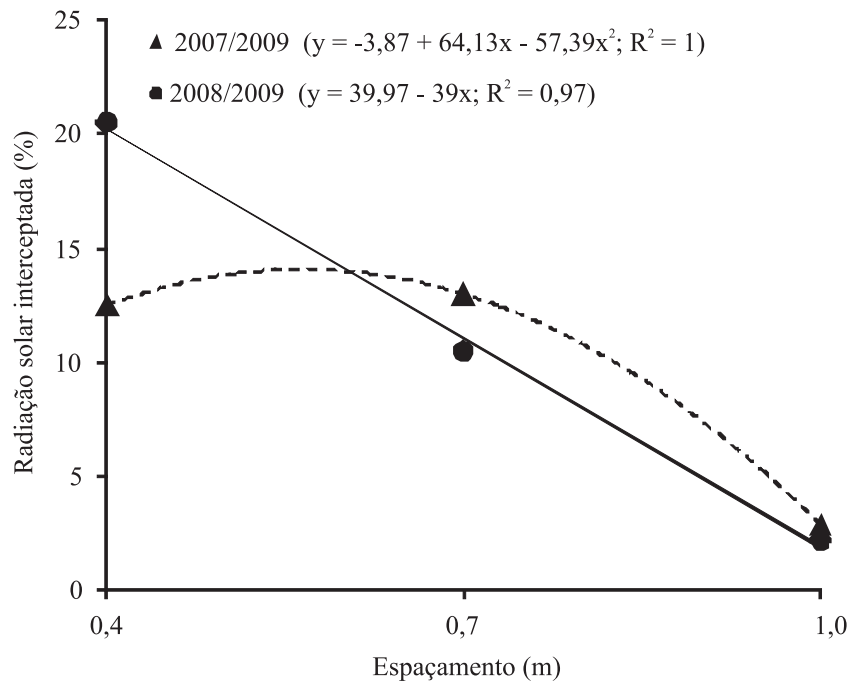

Figura 2. Efeito do espaçamento entre linhas sobre a percentagem de radiação solar interceptada pela cultura do milho com seis folhas expandidas (V6), na média de quatro densidades de plantas, nos anos agrícolas 2007/2008 e 2008/2009. Coeficiente de variação de $2007 / 2008=64,3 \%$ e de $2008 / 2009=84,5 \%$.
$2,9 \%$ no espaçamento de $1,0 \mathrm{~m}$. Na primavera/verão de 2008/2009, a radiação interceptada pelo milho em V6 decresceu linearmente com o aumento do espaçamento entre linhas, tendo passado de $25,4 \%$, no espaçamento de $0,4 \mathrm{~m}$, para $2,1 \%$ no espaçamento de $1,0 \mathrm{~m}$, na média das quatro densidades de plantas (Figura 2). Kunz et al. (2007) também verificaram incremento na interceptação da radiação solar com a redução do espaçamento entre linhas, de 0,8 para $0,4 \mathrm{~m}$.

Não houve efeito significativo dos tratamentos sobre a radiação interceptada nas avaliações feitas em V15, VT e R3. Mesmo na densidade mais baixa (três plantas por metro quadrado) e no espaçamento entre linhas mais amplo (1,0 m), os valores de interceptação mensurados foram sempre superiores a $88 \%$, a partir de V15. Isso indica que, independentemente do arranjo de plantas, o dossel alcançou o IAF crítico, definido por Andrade \& Sadras (2003) como aquele necessário para interceptar $90 \%$ da radiação incidente. Marchão et al. (2006) não encontraram efeito significativo do aumento da densidade de plantas na interceptação da radiação solar, ao medir a radiação absorvida pela parte inferior do dossel, possivelmente porque as leituras foram efetuadas ao nível do solo, no meio das entrelinhas de semeadura.

O IAF foi afetado pelo efeito simples da densidade de plantas, nos dois anos agrícolas (Figuras $3 \mathrm{~A}$ e B). Em 2007/2008 e 2008/2009, o IAF do colmo principal aumentou linearmente com o incremento na população. Esse comportamento é comum na cultura do milho, pois sua área foliar é pouco afetada por variações na densidade, em virtude da baixa plasticidade vegetativa da espécie (Argenta et al., 2001; Strieder et al., 2007; Piana et al., 2008). O aumento na densidade de plantas resultou no incremento do IAF e na diminuição da percentagem de plantas perfilhadas no florescimento e, consequentemente, do IAF mensurado nos perfilhos.

Um dos maiores problemas da utilização de baixas populações em milho é a redução na interceptação da radiação solar (Piana et al., 2008), em razão do não perfilhamento e do baixo incremento no número e no tamanho das folhas (Madonni et al., 2001). Assim, espera-se que os maiores valores de IAF sejam observados em altas populações. Esse comportamento, no entanto, não foi observado neste trabalho, em que os maiores valores de IAF total foram registrados na densidade de três plantas por metro quadrado. Segundo Lauer et al. (2004), o milho deve alcançar valores de 
IAF entre 4 e 5, no florescimento, para otimizar seu desempenho agronômico. No presente trabalho, o IAF total foi superior a 5 em todos os tratamentos (Figura 3), o que indica que o perfilhamento nas menores densidades
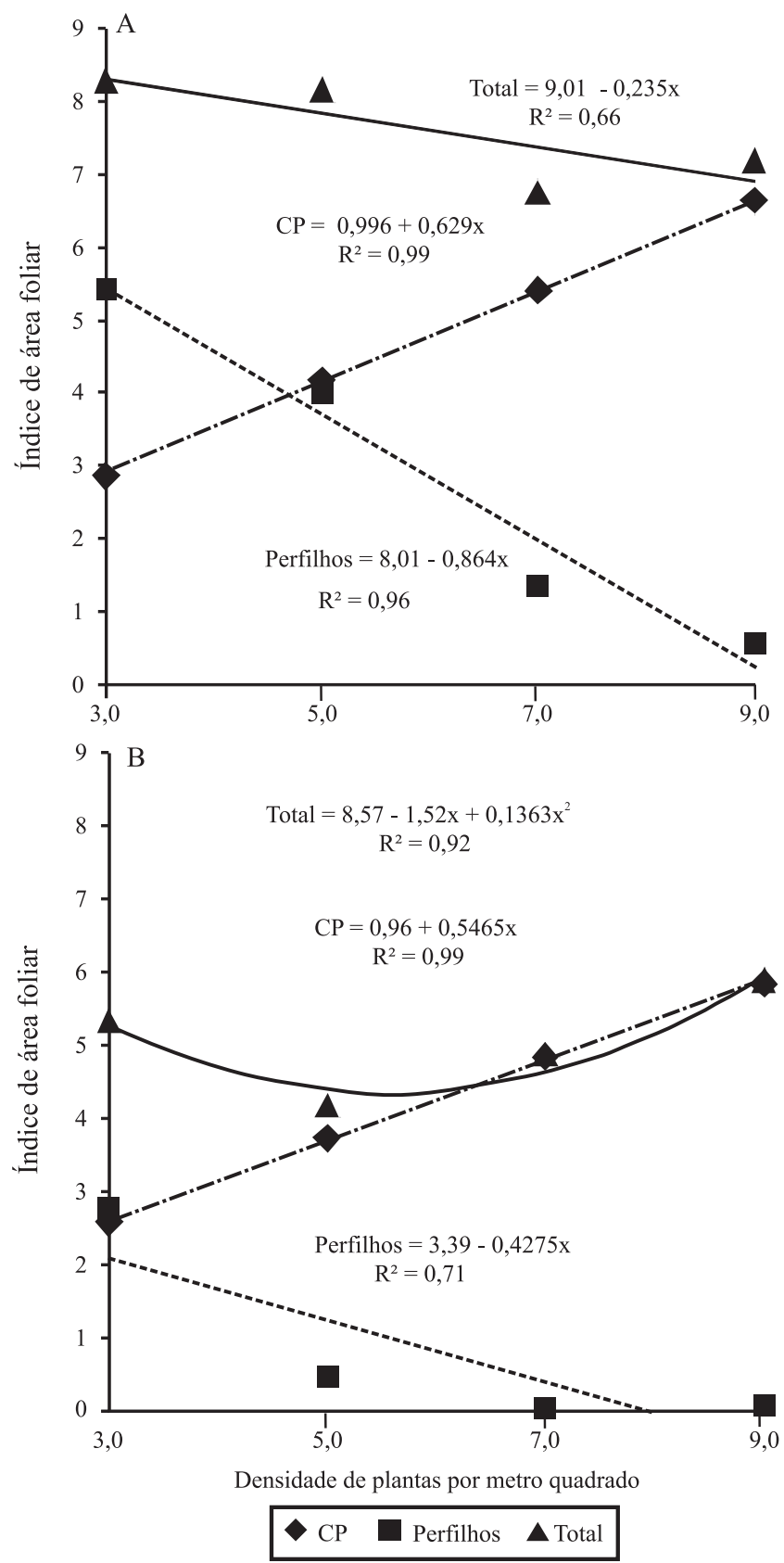

Figura 3. Efeito da densidade de plantas sobre o índice de área foliar do colmo principal (CP), dos perfilhos e total, na média de três espaçamentos entre linhas, em 2007/2008 (A) e 2008/2009 (B). Coeficiente de variação de $\mathrm{CP}=22,85 \%$, Perfilhos $=25,55 \%$ e Total $=12,83 \%$ para A, e CP $=10,22 \%$, Perfilhos $=47,73 \%$ e Total $=12,39 \%$ para B. aumentou a plasticidade vegetativa do milho, tendo propiciado condições para alcançar o IAF crítico na floração, mesmo com estandes sub-ótimos.

Os menores valores de IAF total foram observados em 2008/2009 (Figura 3). Isso pode ser explicado pela deficiência hídrica ocorrida entre V15 e R1 (Figura $1 \mathrm{~B}$ ) - que limitou a expansão das folhas mais jovens e acelerou a senescência das mais velhas (Schussler \& Westgate, 1994) -, e pela menor percentagem de plantas perfilhadas, já que houve menor contribuição dos perfilhos na definição do IAF total, os quais contribuíram com o aumento da área foliar somente até a densidade de cinco plantas por metro quadrado (Figura 3 B).

A percentagem de plantas com espigas nos perfilhos foi afetada pela densidade de plantas, nos dois anos agrícolas. Em 2007/2008, mais de 90\% das plantas apresentavam espigas nos perfilhos, na densidade de três plantas por metro quadrado (Figura 4A). Esse valor decresceu quadraticamente à medida que a densidade aumentou, tendo sido inferior a $10 \%$ na densidade de nove plantas por metro quadrado. Em 2008/2009, 89\% das plantas apresentava perfilhos férteis na colheita, na densidade de três plantas por metro quadrado. Contudo, a fertilidade dos perfilhos foi reduzida drasticamente com a elevação da densidade: 14,9, 4,2 e 1,7\% para as densidades de cinco, sete e nove plantas por metro quadrado, respectivamente.

Em 2008/2009, os períodos de deficiência hídrica ocorridos entre $\mathrm{V} 15$ e R1 e a partir de R3 provavelmente reduziram a sobrevivência dos perfilhos e diminuíram a sua capacidade de produzir espigas na colheita, nas densidades mais altas (Figura $1 \mathrm{~B}$ ). $\mathrm{O}$ aumento na densidade de plantas, associado às condições de estresse ocasionadas pela deficiência hídrica ou nutricional, acentua a dominância apical (Sangoi et al., 2009). Assim, observou-se o aumento da mortalidade dos perfilhos e a redução de sua capacidade de produzir espigas na colheita. Esse comportamento foi confirmado pelo número de espigas de perfilhos por planta, que também sofreu redução quadrática com a elevação na densidade de plantas (Figura 4 B). A redução foi mais pronunciada em 2008/2009, quando não houve produção de espigas nos perfilhos com milho cultivado nas densidades de sete e nove plantas por metro quadrado.

Na safra 2007/2008, a produtividade média total de grãos, de 13,77 $\mathrm{Mg} \mathrm{ha}^{-1}$, não foi afetada pela densidade 
de plantas e pelo espaçamento entre linhas (Figura $5 \mathrm{~A}$ ). A produtividade de grãos do colmo principal aumentou com o acréscimo da densidade de plantas, com produção de 7,51 $\mathrm{Mg} \mathrm{ha}^{-1}$, na menor densidade, e 13,62 $\mathrm{Mg} \mathrm{ha}^{-1}$, próximo à produtividade máxima, na densidade de 8,9 plantas por metro quadrado. A produtividade de grãos dos perfilhos reduziu com o acréscimo da densidade de plantas na proporção inversa do colmo principal, de $5,98 \mathrm{Mg} \mathrm{ha}^{-1}$, na densidade de três plantas por metro
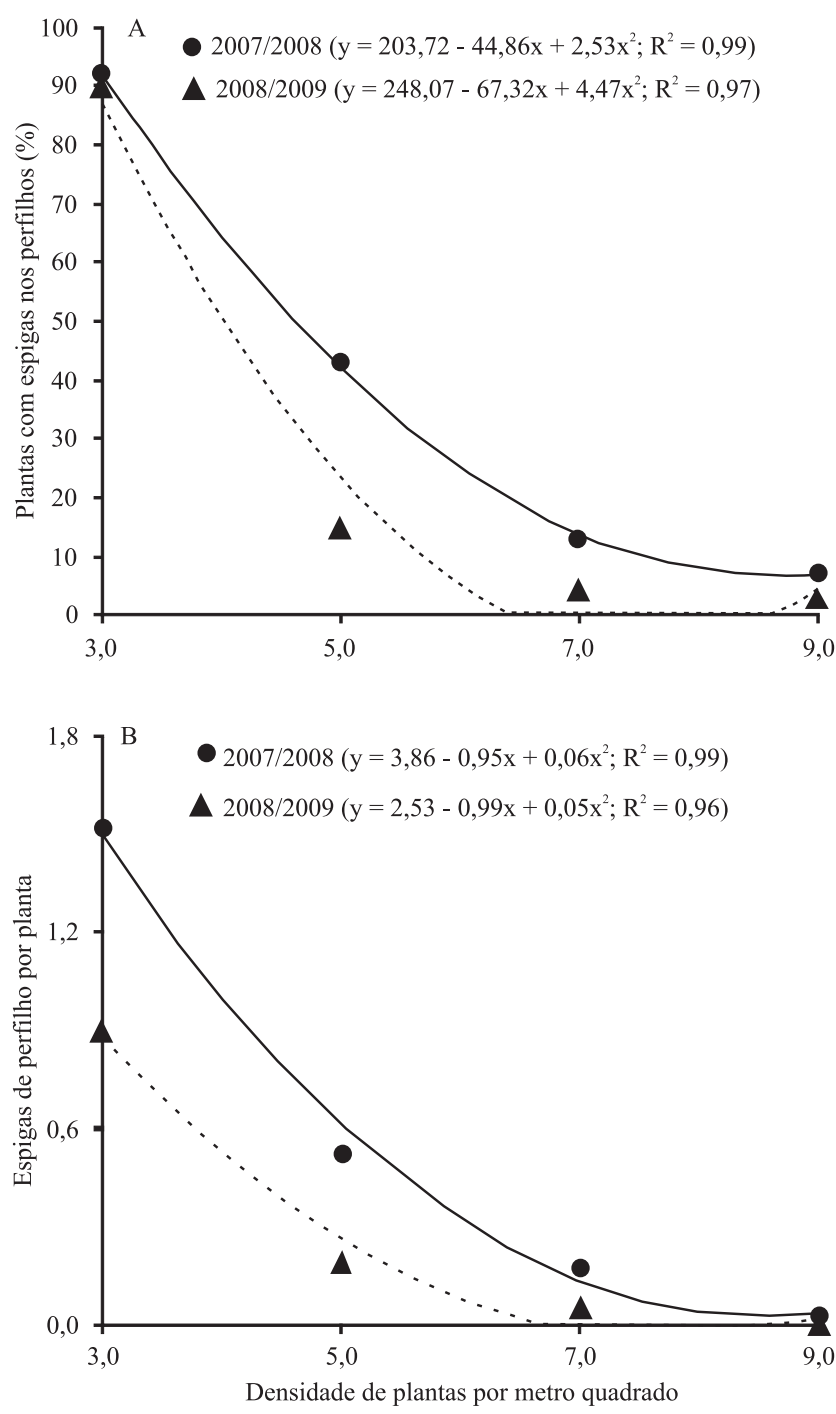

Figura 4. Efeito da densidade de plantas sobre a percentagem de plantas com espigas nos perfilhos em 2007/2008 e 2008/2009 (A), e número de espigas de perfilhos por planta em 2007/2008 e 2008/2009 (B), na média de três espaçamentos entre linhas. Coeficientes de variação de $\mathrm{A}=$ $16,54 \%(2007 / 2008)$ e $43,18 \%$ (2008/2009), e B $=22,85 \%$ (2007/2008) e 49,01\% (2008/2009). quadrado, até o ponto mínimo de $0,46 \mathrm{Mg} \mathrm{ha}^{-1}$, na densidade de 8,3 plantas por metro quadrado.

No segundo ano de avaliação, a produtividade média total de grãos foi menor $\left(10,99 \mathrm{Mg} \mathrm{ha}^{-1}\right)$ do que em 2007/2008 e respondeu de forma quadrática ao efeito simples da densidade de plantas (Figura 5 B), tendo variado de $9,71 \mathrm{Mg} \mathrm{ha}^{-1}$, na densidade de três plantas
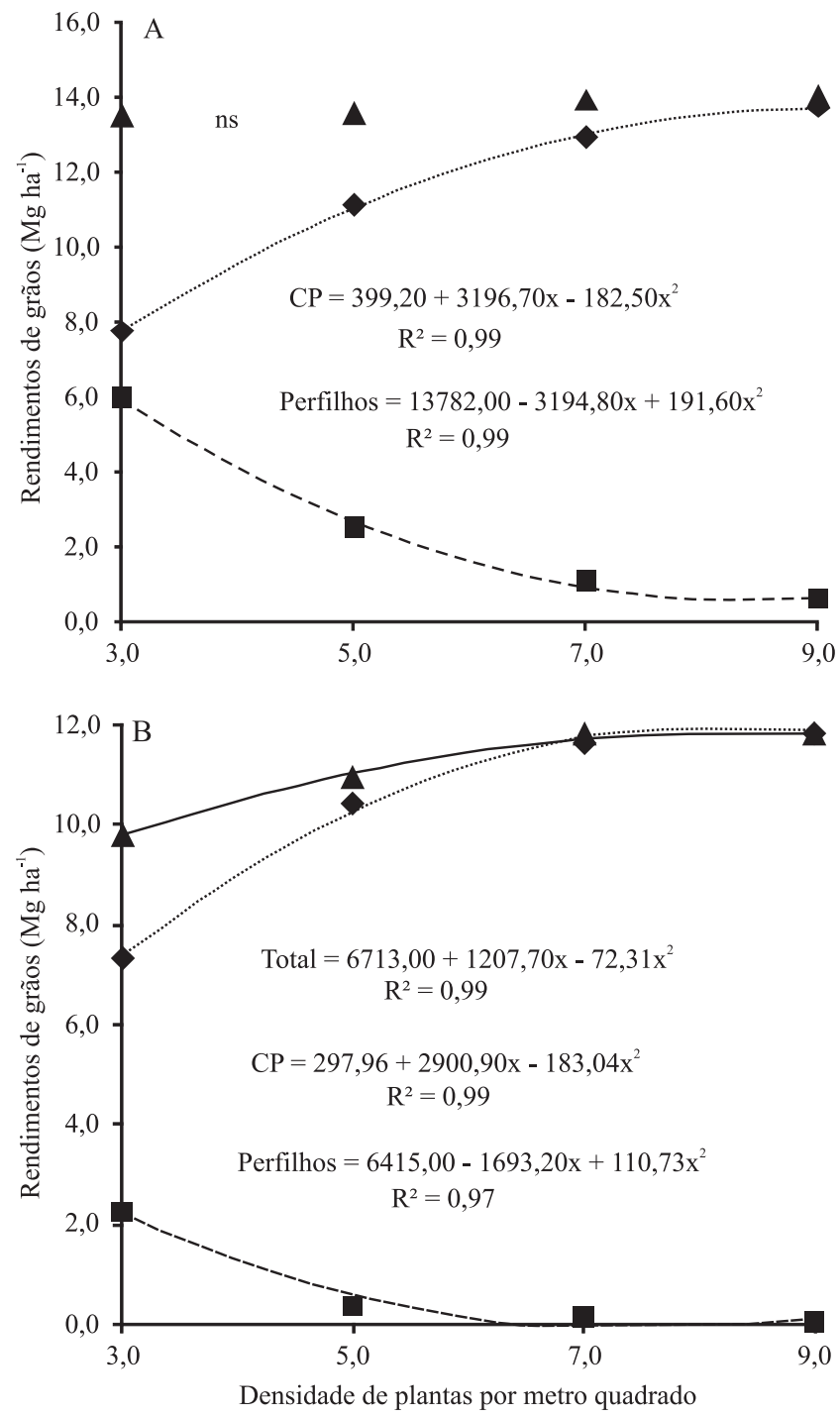

$\Delta$ Total $\triangleright \mathrm{CP} \quad \boldsymbol{\square}$ Perfilhos

Figura 5. Efeito da densidade de plantas sobre a produtividade de grãos do colmo principal (CP), dos perfilhos e total em 2007/2008 (A) e 2008/2009 (B), na média de três espaçamentos entre linhas. Coeficiente de variação Total $=5,61 \%$, $\mathrm{CP}=4,90 \%$ e Perfilho $=17,80 \%$ para A, e Total $=5,61 \%$, $\mathrm{CP}=5,44 \%$ e Perfilho $=44,63 \%$ para B. ns, Não significativo a $5 \%$ de probabilidade. 
por metro quadrado, a 11,7 $\mathrm{Mg} \mathrm{ha}^{-1}$ na densidade de nove plantas por metro quadrado, o que corresponde a um incremento de $20,6 \%$ na produtividade quando se triplicou a densidade de plantas. Demétrio et al. (2008) obtiveram resultados semelhantes. De forma semelhante ao observado no primeiro ano, a produtividade de grãos do colmo principal aumentou quadraticamente com o aumento da densidade, tendo atingido seu máximo na densidade de 7,9 plantas por metro quadrado. Já a produtividade de grãos dos perfilhos, diminuiu quadraticamente com o aumento na população.

As populações de plantas recomendadas para os híbridos de milho cultivados no Brasil variam de 5,5 a 7,0 plantas por metro quadrado, em condições favoráveis de clima e solo (Argenta et al., 2001). No primeiro ano, o perfilhamento em estandes subótimos propiciou a obtenção de valores de IAF superiores ao das maiores densidades (Figura 3A). A produção de grãos nos perfilhos, nesse ano, contribuiu com $44 \%$ da produtividade total de grãos, na densidade de três plantas por metro quadrado, o que impediu reduções significativas na produtividade do milho.

A menor participação dos perfilhos na definição da produtividade total de grãos, em 2008/2009 foi a principal responsável pela maior resposta do milho à elevação da densidade de plantas, nesse ano agrícola. No entanto, apesar da condição hídrica menos favorável, os perfilhos produziram 2,39 $\mathrm{Mg} \mathrm{ha}^{-1}$ na densidade de três plantas por metro quadrado, o que correspondeu a $25 \%$ da produtividade total. Isso permitiu que a produtividade total obtida com a metade da densidade recomendada para o híbrido P30F53 fosse $92 \%$ superior à produtividade média do Estado de Santa Catarina, de 5,05 $\mathrm{Mg} \mathrm{ha}^{-1}$, na safra primavera/verão de 2008/2009 (Companhia Nacional de Abastecimento, 2010).

Esperava-se que a redução do espaçamento entre linhas e a distribuição mais equidistante das plantas, dentro de cada densidade, estimulassem o perfilhamento e aumentassem a contribuição dos perfilhos à produtividade de grãos; no entanto, esta hipótese não foi confirmada no presente trabalho. Argenta et al. (2001) e Strieder et al. (2008) também não relataram incremento na produtividade de grãos com a redução do espaçamento entre linhas. De acordo com os autores, os efeitos desta prática cultural dependem do híbrido e do nível tecnológico utilizado na lavoura. Os dados obtidos nos dois anos avaliados indicam que o perfilhamento é uma característica desejável para a estabilidade produtiva do híbrido P30F53, pois minimiza os prejuízos à produtividade ocasionados pelo uso de baixas densidades e torna o milho menos sensível às variações no arranjo de plantas (Figura 5). Comportamento semelhante foi observado por Lafarge (2000), Chen et al. (2010) e Lampayan et al. (2010) para as culturas do trigo, cevada e arroz, respectivamente.

\section{Conclusões}

1. O perfilhamento aumenta a estabilidade fenotípica da produtividade de grãos de milho frente a variações no arranjo de plantas.

2. A redução do espaçamento entre linhas aumenta a interceptação da radiação solar no início do ciclo, mas não interfere na produtividade de grãos do milho.

\section{Agradecimentos}

Ao Conselho Nacional de Desenvolvimento Científico e Tecnológico e à Coordenação de Aperfeiçoamento de Pessoal de Nível Superior, pela concessão de bolsas.

\section{Referências}

AKMAN, Z. Effect of tiller removing and plant density on ear yield of sweet corn (Zea mays saccharata Sturt). Pakistan Journal of Biological Sciences, v.5, p.906-908, 2002.

ALMEIDA, M.L. de; SANGOI, L.; MEROTTO JUNIOR, A.; ALVES, A.C.; NAVA, I.C.; KNOPP, A. Tiller emission and dry mass accumulation of wheat cultivars, under different stress. Scientia Agricola, v.61, p.266-270, 2004.

ANDRADE, F.H.; SADRAS, V.O. Bases para el manejo del maíz, el girassol e la soja. Buenos Aires: Editorial Médica Panamericana, 2003. 443p.

ARGENTA, G.; SILVA, P.R.F. da; SANGOI, L. Arranjo de plantas em milho: análise do estado-da-arte. Ciência Rural, v.31, p.1075-1084, 2001.

BERGAMASCHI, H. (Coord.). Agrometeorologia aplicada à irrigação. 2.ed. Porto Alegre: UFRGS, 1999. 125p.

CHEN, S.; ZHANG, X.; SUN, H.; REN, T.; WANG, Y. Effects of winter wheat row spacing on evapotranspiration, grain yield and water use efficiency. Agricultural Water Management, v.97, p.1126-1132, 2010.

COMPANHIA NACIONAL DE ABASTECIMENTO. Acompanhamento de safra brasileira de grãos: 9ำ levantamento. Brasília: Conab, 2010. 45p. 
DEMÉTRIO, C.S.; FORNASIERI FILHO, D.; CAZETTA, J.O.; CAZETTA, D.A. Desempenho de híbridos de milho submetidos a diferentes espaçamentos e densidades populacionais. Pesquisa Agropecuária Brasileira, v.43, p.1691-1697, 2008.

DOEBLEY, J. The genetics of maize evolution. Annual Review of Genetics, v.38, p.37-59, 2004.

KUNZ, J.H.; BERGONCI, J.I.; BERGAMASCHI, H.; DALMAGO, G.A.; HECKLER, B.M.M.; COMIRAN, F. Uso da radiação solar pelo milho sob diferentes preparos do solo, espaçamento e disponibilidade hídrica. Pesquisa Agropecuária Brasileira, v.42, p.1511-1520, 2007.

LAFARGE, M. Phenotypes and the onset of competition in spring barley stands of one genotype: daylength and density effects on tillering. European Journal of Agronomy, v.12, p.211-223, 2000 .

LAMPAYAN, R.M.; BOUMAN, B.A.M.; DIOS, J.L. de; ESPIRITU, A.J.; SORIANO, J.B.; LACTAOEN, A.T.; FARONILO, J.E.; THANT, K.M. Yield of aerobic rice in rainfed lowlands of the Philippines as affected by nitrogen management and row spacing. Field crops research, v.116, p.165-174, 2010.

LAUER, J.G.; ROTH, G.W.; BERTRAM, M.G. Impact of defoliation on corn forage yield. Agronomy Journal, v.96, p.1459-1463, 2004.

MARCHÃO, R.L.; BRASIL, E.M.; XIMENES, P.A. Interceptação da radiação fotossinteticamente ativa e rendimento de grãos de milho adensado. Revista Brasileira de Milho e Sorgo, v.5, p.170-181, 2006.

MOULIA, B.; LOUP, C.; CHARTIER, M.; ALLIRAND, J.M.; EDELIN, C. Dynamics of architectural development of isolated plants of maize (Zea mays L.), in a non-limiting environment: the branching potential of modern maize. Annals of Botany, v.84, p.645-656, 1999.
PIANA, A.T.; SILVA, P.R.F. da; BREDEMEIER, C.; SANGOI, L.; VIEIRA, V.M.; SERPA, M. da S.; JANDREY, D.B. Densidade de plantas de milho híbrido em semeadura precoce no Rio Grande do Sul. Ciência Rural, v.38, p.2608-2612, 2008.

RITCHIE, S.W.; HANWAY, J.J.; BENSON, G.O. How a corn plant develops? Ames: Iowa State University of Science and Technology, 1993. 26p. (Special report, 48).

SANGOI, L.; SCHMITT, A.; SALDANHA, A.; FIORENTIN, C.F.; PLETSCH, A.J.; VIEIRA, J.; GATELLI, M.A. Rendimento de grãos de híbridos de milho em duas densidades de plantas com e sem a retirada dos perfilhos. Ciência Rural, v.39, p.325-331, 2009.

SANGOI, L.; SCHMITT, A.; ZANIN, C.G. Área foliar e rendimento de grãos de híbridos de milho em diferentes populações de planta. Revista Brasileira de Milho e Sorgo, v.6, p.263-271, 2007.

SANTOS, H.G. dos; JACOMINE, P.K.T.; ANJOS, L.H.C. dos; OLIVEIRA, V.A. de; OLIVEIRA, J.B. de; COELHO, M.R.; LUMBRERAS, J.F.; CUNHA, T.J.F. (Ed.). Sistema brasileiro de classificação de solos. 2.ed. Rio de Janeiro: Embrapa Solos, 2006. 306p.

SCHUSSLER, J.R.; WESTGATE, M.E. Increasing assimilate reserves does not prevent kernel abortion at low water potential in maize. Crop Science, v.34, p.1569-1576, 1994.

STRIEDER, M.L.; SILVA, P.R.F. da; ARGENTA, G.; RAMBO, L.; SANGOI, L.; SILVA, A.A. da; ENDRIGO, P.C. A resposta do milho irrigado ao espaçamento entrelinhas depende do híbrido e da densidade de plantas. Ciência Rural, v.37, p.634-642, 2007.

STRIEDER, M.L.; SILVA, P.R.F. da; RAMBO, L.; SANGOI, L.; SILVA, A.A. da; ENDRIGO, P.C.; JANDREY, D.B. Crop management systems and maize grain yield under narrow row spacing. Scientia Agricola, v.65, p.346-353, 2008.

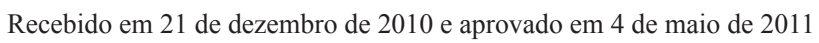

